\title{
Correction to: Endolymphatic sac enlargement in an infant with metabolic acidosis
}

\author{
Emre Leventoğlu ${ }^{1}$ (1) $\cdot$ Kibriya Fidan $^{1} \cdot$ Cansu Girgin ${ }^{2} \cdot$ Merve Yazol $^{3} \cdot$ Şeyda Varol ${ }^{3} \cdot$ Oğuz Söylemezoğlu $^{1}$
}

Published online: 10 July 2021

(C) Italian Society of Nephrology 2021

\section{Correction to: Journal of Nephrology https://doi.org/10.1007/s40620-021-01085-z}

In the original article published, The Fig. 2 and caption was missing. The correct figure legend is

"Schematic illustration detailing the anatomy of the endolymphatic system. The left diagram shows the normal structure of an endolymphatic sac; and the right diagram shows an enlarged endolymphatic sac. Illustration modified after NIDCD (2017) Enlarged Vestibular Aqueducts and Childhood Hearing Loss. U.S. Department of Health and Human Services, National Institutes of Health. https://www.nided. nih.gov/health/enlarged-vestibular-aqueducts-and-child hood-hearing-loss".

The original article can be found online at https://doi.org/10.1007/ s40620-021-01085-z.

Emre Leventoğlu

dremrelevent@gmail.com

1 Faculty of Medicine, Department of Pediatric Nephrology, Gazi University, Ankara, Turkey

2 Faculty of Medicine, Nephrogenetics Laboratory, Gazi University, Ankara, Turkey

3 Faculty of Medicine, Department of Radiology, Gazi University, Ankara, Turkey 
Fig. 2 Schematic illustration detailing the anatomy of the endolymphatic system. The left diagram shows the normal structure of an endolymphatic sac; and the right diagram shows an enlarged endolymphatic sac. Illustration modified after NIDCD (2017) Enlarged Vestibular Aqueducts and Childhood Hearing Loss. U.S. Department of Health and Human Services, National Institutes of Health. https://www. nidcd.nih.gov/health/enlargedvestibular-aqueducts-and-child hood-hearing-loss

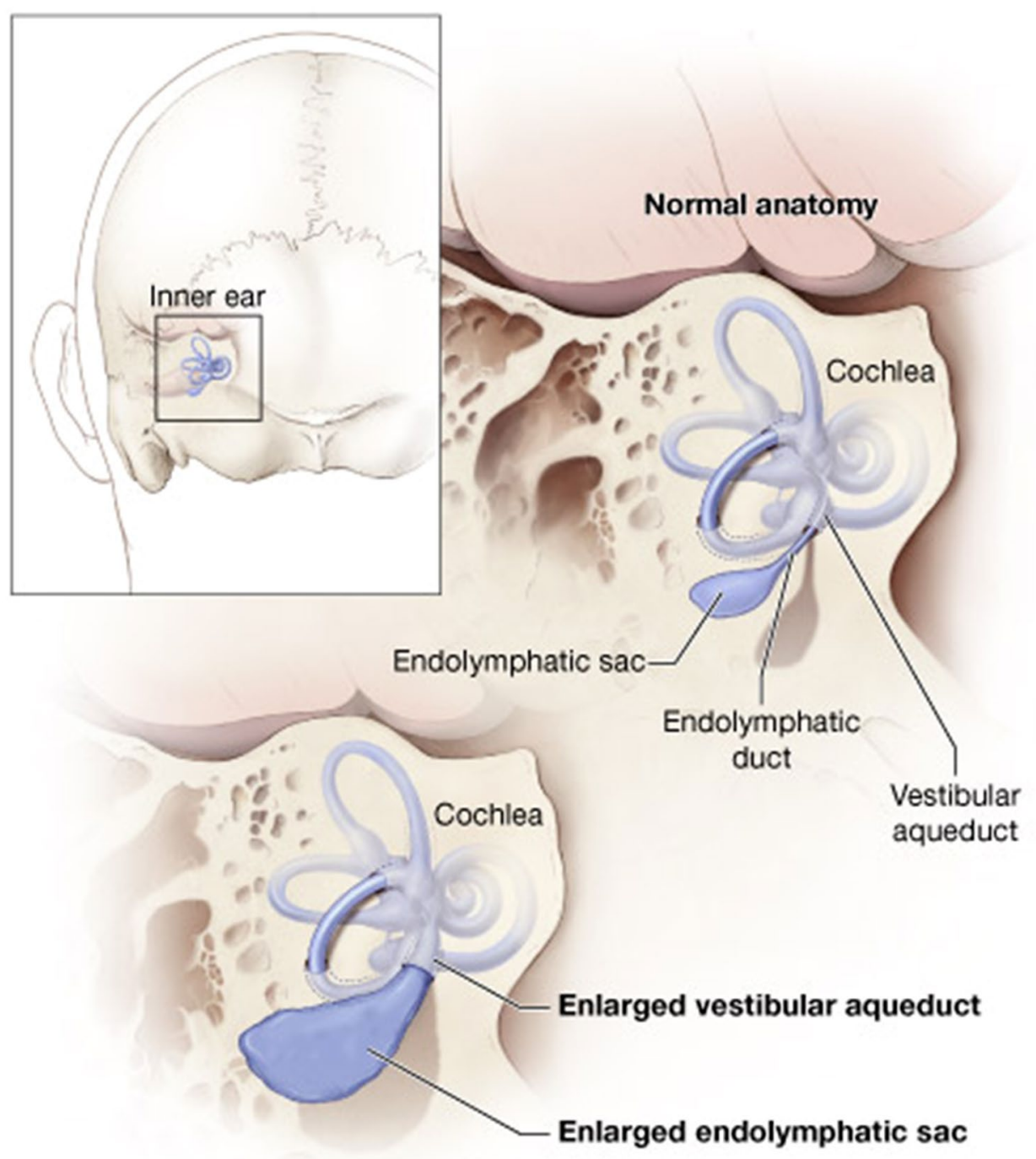

Enlarged endolymphatic sac

\section{Declarations}

Conflict of interest The authors have no conficts of interest to disclose.

Ethical approval Ethics board approval of Gazi University Faculty of Medicine was granted and conformed to the ethical guidelines of the Helsinki Declaration (as revised in Tokyo 2004).
The original article has been corrected.

Publisher's Note Springer Nature remains neutral with regard to jurisdictional claims in published maps and institutional affiliations. 